\title{
BlaBlaCar: Value Creation on a Digital Platform
}

\author{
Deepak Saxena $^{1}$, Laurent Muzellec ${ }^{1}$ and Daniel Trabucchi ${ }^{2}$ \\ ${ }^{1}$ Trinity College Dublin, Ireland 2Politecnico di Milano, Italy
}

\begin{abstract}
From its humble origin in 2003, BlaBlaCar has become a preferred ride-sharing platform for the passengers across Europe. BlaBlaCar is an online marketplace that connects drivers and passengers and helps them share the costs of journeys. In so doing, it creates value for both sides of the platform. Drivers save money of the cost of the trip, and passengers get a low cost option to reach their destination. The case follows the company from the inception to its growth and current challenges. The case helps the students in understanding the business of digital platforms as it relate to value creation for the customers, matching the value proposition for two sides, revenue and pricing strategies, and the crucial role of trust in sharing economy.
\end{abstract}

This is the post-print version of the paper "BlaBlaCar: Value Creation on a Digital Platform" published in the Journal of Information Technology Teaching Cases. The full reference is the following:

Deepak, S., Muzellec, L. and Trabucchi, D. (2020). "BlaBlaCar: Value Creation on a Digital Platform", Journal of Information Technology Teaching Cases. Doi: 10.1177/2043886919885940

\section{Introduction}

On April 24, 2018, the trains in France were on strike (again). For the international press, strikes are an opportunity to mock French labour laws or praise workers' esprit de corps in defending their rights. For the commuters, however, strikes are neither a laughable matter nor a source of pride. Strikes have practical implications on commuters that include being stranded, missing work or a family reunion, getting a much longer commute, or squeezing into one of the few trains which are still running. However, over the last few years, an Internet platform has considerably contributed to minimising the inconvenience caused by such events to commuters: BlaBlaCar.

BlaBlaCar is an online marketplace that connects drivers and passengers and helps them share the costs of journeys. On April 24, 2018, Fred plays the role of a driver and takes on board a retired couple who were using BlaBlaCar for the first time. He listens to their complaints about the railroad service but also the difficulties they encountered when signing up on BlaBlaCar. As they did not have a Facebook account, they created one before they could sign up on the platform. It took them a while to complete all the formalities. In the end, they are delighted to be in the car with Fred, on the way to see their grandchildren. Fred listens carefully and thinks of the solutions that could improve their experience. This is because Fred is no ordinary member of the BlaBlaCar community. In fact, Fred is the founder of the company. He uses every trip as an opportunity to understand consumers' needs and concerns better and think of solutions and/or innovations. 


\section{How the idea was born?}

Around fifteen years ago in December 2003, Fred Mazella was trying to go to his hometown in the Vendée region (west of France), $500 \mathrm{~km}$ away from Paris, to spend Christmas with his family. All trains were fully booked during the busy period, and no seats were available until after Christmas. Eventually, he managed to convince his sister to pick him up from Paris, a major detour for the sibling who lived in Normandy. As he was driving with her on the highway, he saw a train that he wanted to take. It was indeed overbooked with all seats occupied. At the same time, whizzing past his car were hundreds of cars that were mostly empty except for the drivers. It was a eureka moment! Fred thought, "Oh my God, there are seats for going to Vendee, but they are not on trains. They are on cars!" He wondered about a platform that could enable people who did not have cars to get lifts and drivers to find passengers who would share the cost of trips. He spent the next few days doing an online search for platforms connecting passengers and drivers. However, all he could find were some fairly confidential forums that were so unorganised that finding someone who was taking the same trip at the same time was practically impossible. His research convinced him of two things. First, the need for such types of services indeed existed, and he was not the only one in France in need of a ride to go home; in fact, a small community of users had started to emerge via those forums. Second, what really needed was a platform equipped with a powerful algorithm that could match passengers and drivers based on the date of departure, the point of departure, and the point of arrival.

For the next three years, Fred would spend his time coding for the platform with two school friends, now engineers. When not coding, Fred would go to weekly entrepreneurial meetups to discuss his ideas and gain feedback. It was in one such forums that he met Francis Nappez, a technology expert, who offered his services if Fred decided to use the mobile platform. Soon realising his lack of skills in marketing, management, and product development, Fred started an MBA at INSEAD. During his MBA, Fred not only learnt about the best business practices but also tested and refined several business models for his idea. It was at INSEAD that he met Nicolas Brusson who was immensely interested in the venture capital world and start-up ecosystem. In 2006, Fred purchased the domain name Covoiturage.fr (French for 'car sharing') and along with Nicolas and Francis (see Appendix 1 for brief bio of founders) founded a company called Comuto ${ }^{1}$. Fred realised that the reason why car sharing had not fully taken off earlier was not because of the lack of interest from the potential users but rather because no platforms had successfully managed to match passengers and drivers using the date and time of departure, travel origin, and travel destination. Now, Fred had a working platform that offered the best possible solution based on the three variables. With a working platform and tentative business model, it was now time to market the services to a wider audience. Although the company had rapidly become the market leader in France, it required the final impetus to become a household name.

\section{Seizing the opportunities and facing scaling challenges}

In October 2007, Fred's sister Helene saw an opportunity and immediately called Fred. "Next week there's going to be a train strike", she said over the phone, "You've got to own this moment and send out a press release!" What seemed a normal Sunday afternoon in October 2007 suddenly turned into an all-night workshop for the siblings. As a communications expert, Helene helped Fred craft a message that portrayed BlaBlaCar as a travel option during the strikes and advised him to send the press release out first thing on Monday morning.

Merely 30 minutes after sending the press release, Reuters and AFP picked up the news and circulated it. Within seconds, Fred's phone began continuously ringing, and he could not sleep for the next 48 hours. He ended up being on the TV and radio, and the platform was featured in over 500 newspaper

\footnotetext{
${ }^{1}$ Until April 2012, 'Commuto' was the brand name used in Spain, and until 2013, 'Covoiturage' was the brand name used in France.
} 
articles. It was massive publicity, and for the first time, BlaBlaCar was thrown into the limelight. The fact that the platform was available on mobile to help everybody find alternative transport options during the train strikes was significant. As Fred was approached by many media outlets, Francis and the rest of the team were working full throttle behind the scenes. Owing to the increase in traffic, they made continuous changes in the code to adapt to the new volumes. The first version of the platform could only handle up to 100,000 members. When Francis formally joined the company full time in 2008, he modified the platform architecture to accommodate another 5 million members. They continued to modify the platform to support further user growth. The platform was now on the radar of French media and would soon become a recurring topic every time there was a strike, which was indeed frequent (see Appendix 2).

The train strikes of 2007 helped BlaBlaCar become a household name in France. But now, it was time to think big and grow internationally. Once again, a shot in the arm came from an unexpected event. An Icelandic volcano started erupting on April 14, 2010, and ejected a significant amount of volcanic ash into the atmosphere, creating a potential hazard for aeroplanes. For the next six days, as the ash diffused the European airspace, fleets of airlines remained stationed, leaving approximately 10 million passengers stranded at European airports. BlaBlaCar again became a preferred solution for people stranded far from home and, in one case, for a bride who had to reach the wedding venue. Frequent strikes in France further helped the company expand its market base.

However, while such strikes and disruptions are treated as 'gold dust' by the company, platform business has its own share of complications. The main issue with such types of platform is the ability to attract both sides of the markets simultaneously. For the platform to be successful, both groups of customers - the consumers (passengers) and the producers (drivers) - need to be on the network. One group will not come to the network unless the other does and vice versa. This situation is commonly known as the 'chicken and egg paradox'. In the case of BlaBlaCar, passengers and drivers are the two groups of customers of the platform. While the passengers join the platform to search for rides offered by drivers, drivers search for passengers to share their travel costs. BlaBlaCar offers a service to both. Train strikes constitute a wonderful opportunity to advertise the services to both sides of the network, but the company may face problems balancing the supply with the demand.

Fred recalls that while the number of passengers was growing rapidly, enough drivers were not available to offer rides. This problem was especially acute during strikes, as they brought more passengers than drivers. After considerable contemplation, Fred and his team found a solution to the problem: emotional marketing. In this regard, Fred recounts, "During a train strike, we started just calling for drivers, asking for solidarity with passengers, saying 'Ok, trains are on strike, lots of passengers will be without a way to move around, please drivers, if you have empty seats propose your seats because there are plenty of passengers searching for a ride'"'. The messages were available across various marketing channels from the press to social media. The notion of solidarity hit a chord with the drivers in those difficult moments.

\section{Experimenting with business models}

Interestingly, while the company made strides in terms of its user base and there was no dearth of venture capital (see Appendix 3), it struggled to find the right business segment and pricing model. The idea of a carpooling platform had a potential for both individual and business consumers. Back in 2007, the company received many requests from businesses and local authorities in France interested in integrating a carpooling platform with their corporate intranet. Their main focus was facilitating home-work travel over short distances (usually less than $20 \mathrm{~km}$ ). While this purpose was not aligned with Fred's original idea of long-distance travel (averaging $300 \mathrm{~km}$ ) between cities, it still was a lucrative option to customise the platform for other business. Carrefour, IKEA, and some hospitals in Marseille were among the first to integrate the platform within their portal. Over the years, around 
200 companies utilised the service. In 2009, BlaBlaCar earned approximately $€ 10 \mathrm{k}$ per month from the sales of their platforms to businesses. Although it was a steady source of revenue for BlaBlaCar, it required investing considerable time, resources, and attention to deliver such multiple customised platforms to various companies. Another issue for the company was that the solution was not scalable due to the differing requirements of customers. Over time, it became clear to Fred and his team that the business-to-business (B2B) model would not flourish. Eventually, the decision to phase out the B2B model was taken in 2012.

The closure of the B2B platform service allowed the company to exclusively focus on the C2B2C (or $B 2 C \& C)$ model where the platform would enable transactions between the two sides of a market. Two-sided markets are economic platforms having two distinct user groups that provide each other with network benefits. In the case of BlaBlaCar, the two sides are passengers and the drivers. They benefit from and provide economic benefits to each other. The drivers can subsidise the costs of their trips by sharing the costs of travel ${ }^{1}$. The passenger(s) also benefit from reduced prices as well as increased flexibility compared to the time, pick up and destination options available via public transport. The network benefits are known as cross-side network externalities. This means that the value of the platform for the passengers depends on the rides offered by the drivers, and at the same time, the value for the drivers depends on the passengers asking for rides.

Within this model, however, BlaBlaCar still needed to figure out its revenue and pricing scheme. For some time, a Freemium model was adopted in which the overall service remained free and the members had the option to pay for additional services. By paying a monthly or annual fee, the premium members could have the benefit of having their posts ranked higher in search engines and receiving text messages each time they had a request. However, upon further deliberation, it was understood that the option was not fair to other consumers. The team also deemed the option to be financially unviable in the long run. Implementing a monthly subscription plan with a flat fee was also considered. However, the subscription idea was also quickly discarded because of the uneven use of the platform. While some members used the platform sporadically (a few times per year), some others used it frequently (several times a week). Consequently, it was impossible to devise a subscription formula that was fair to all. BlaBlaCar also tested the advertising model as the majority of the internet service providers do. However, there were concerns within the team on the possibility of the misuse of the personal data of members by the affiliates for commercial purposes. It was also antithetical to the philosophy of trust (see the next section) that the company followed. Consequently, the company decided not to follow the advertising route, to protect the personal data of their members.

Currently the pricing and revenue model differs from one country to another (see Appendix 4). For instance, the platform is free in the markets that it is penetrating. With this strategy, the company has entered Eastern Europe including Russia, South America, and India. In the matured markets, however, the company follows a transaction-based pricing with the passengers paying the transaction fee. Drivers get the price they ask for, but the passengers pay a slightly higher price to cover the transaction costs. In other words, one of the two sides pays the platform for both, while BlaBlaCar offers a service that matches the two sides (see Figure 1). Fred acknowledges the difficulties associated with the transactional model: "The hardest one is the one (business model) we have, which is the transactional, taking care of the money and their transfer. Moving money from a million of passengers to a million of drivers. And in some cases, you also have to give the money back because the transaction does not happen, and in some cases managing issues between the two".

\footnotetext{
${ }^{1}$ Drivers are supposed to cover only their fuel and road toll costs but not to make a profit from the passengers.
} 


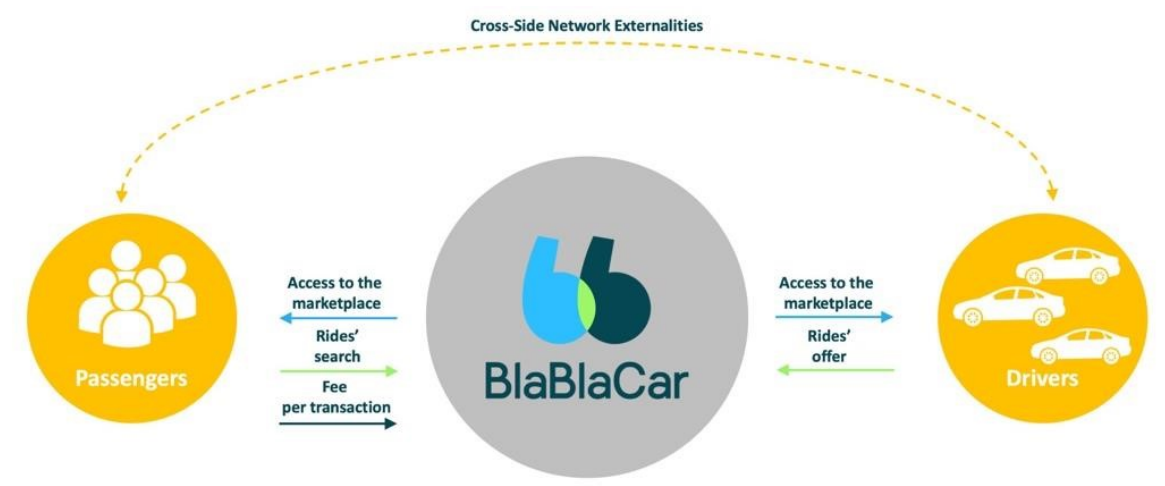

Figure 1 - BlaBlaCar as a Two-Sided Platform

\section{Managing trust and expectations}

Gaining consumer trust is crucial for any business for its long-term survival. In fact, for a C2B2C platform like BlaBlaCar, it is their raison d'être. Most of the commuters would not have met before. That is why they would be using the services of BlaBlaCar at the first place. Establishing trust and rapport traditionally takes time and repeated interactions. At the beginning, the lack of trust was related to many dimensions, from getting in the car with a stranger to the actual chance of finding the passenger at the meeting point or the driver arriving at the defined meeting point. Indeed, overbooking and no show were concerns for the company in the beginning. The drivers overbooked due to the fear of no-shows. The passengers overbooked because they were unsure whether they would get a ride with the driver they booked. This resulted in a vicious circle of overbooking and cancellations with the rate of cancellation peaking up to $35 \%$.

To tackle the issues of overbooking and no show, the company employed the following strategies. First, the company tried with a bidirectional rating system. This worked well for the drivers who saw an increase in their ratings. However, it did not exactly work for the passengers. The passengers with bad feedback would book drivers with good ratings but then would not show up. The rating system resulted in penalising good drivers for unreliable passengers, which led to good drivers leaving the platform. To avoid this situation, the company asked users to pay upfront if they wanted to book a ride. Once the advance payment method was introduced, the number of cancellations reduced to $3 \%$.

Over the years, the company's user interface has evolved to create and manage the trust ecosystem using the six pillars of online trust (see Appendix 5) to gain a 'trust capital'. It encourages its users to make an online trust profile based on verified information, declarative content, and others' ratings from previous experiences. Over the years, more trust features are introduced to create a trust ecosystem. It was found that members with public profile pictures and social network activities were trusted more. Based on this, the platform allows its users to log in through their Facebook accounts, instantly utilising the trust capital built through another platform. After each journey, both the passengers and drivers are encouraged to leave reviews of each other. To ensure that fair and honest ratings are given and discourage 'revenge ratings', the team introduced a feature that allows members to view the rating they received only if they rate their co-travellers within 14 days.

However, the emphasis on trust goes beyond the user interface and forms the backbone of the company's operations. Back in 2012, Fred spoke at a TED event where to the utter surprise of his audience, he tore off his shirt to unveil an orange-green emblem declaring him as Trustman (Figure 2). At the same time, the other members of the team sitting with the audience also unveiled themselves as Trustmen and Trustwomen.

Going beyond symbolism, BlaBlaCar teamed up with Prof. Arun Sundararajan, a sharing economy expert with NYU Stern School of Business, to conduct a continent-wide study on online trust with over 18,000 BlaBlaCar customers across $11 \mathrm{EU}$ countries. To ensure that the results were unbiased and 
trustworthy, BlaBlaCar decided not to sponsor the research but only provide access to their customers. The results of the survey indicate that, in general, people trust members with a full BlaBlaCar profile more than a colleague. In fact, the survey indicates that the level of trust on a BlaBlaCar member is second only to the trust on family and friends. Around $70 \%$ of the users declared that so many drivers and passengers being on the platform makes them feel more comfortable ridesharing with BlaBlaCar.

Apart from trust, the comfort with co-passengers is also a significant factor when sharing a long ride with somebody. To accommodate this, BlaBlaCar introduced preference settings for members to rate themselves on parameters such as smoking preferences or chattiness. For example, while some passengers like to chat a lot with fellow passengers during a journey, some others may prefer to keep the chatter to a minimum and enjoy the scenery. Aligned with the company's name, members can rate themselves $\mathrm{Bla}$, BlaBla, or BlaBlaBla, with the last one denoting most chattiness. This emphasises the social nature of the BlaBlaCar community adds additional value where a rideshare is not just a means to decrease the cost of travel but also an avenue that may help in forging long-term social relations based on one's conversation preferences. Later, the company also introduced verification information based on members' experience level, declared preferences, inclusion of profile photo, percentage of positive ratings received, and their seniority in terms of usage. In the order of reputation and trustworthiness, the experience levels are newcomer, intermediate, experienced, expert, and ambassador. Beyond trust, it also makes economic sense to the members, as ambassadors find it much easier to get their cars quickly filled. Ambassadors are also invited to focus groups where they provide feedback on the new features to be launched. To encourage more participation from members, more recently the company introduced a peer-to-peer chat of helpers (ambassadors who meet certain criteria) to support other members. These helpers work in direct contact with the company teams.

\section{Challenges and legal issues}

As BlaBlaCar grows both in size and its geographical footprint, it also faces diverse challenges. It is finding it difficult to sustain itself in some markets, for example, far off in India, Mexico, Turkey, and closer in the UK. Interestingly, in most of the non-European markets, trust is a major issue. In India, for example, people usually travel long distance with friends and family and do not trust strangers to share a ride. To tackle this cultural roadblock, BlaBlaCar introduced Government ID verification, which requires members to be verified based on existing government IDs. The company planned to introduce it in Mexico and Turkey as well. However, the company failed to get a significant amount of traction for its services and had to close down local offices. The local websites are still operational, though mostly working on an autopilot. BlaBlaCar in the UK is still operational and follows the government ID verification scheme, but Nicolas Brusson (co-founder and CEO) admits that BlaBlaCar "sort of works but it's nothing exciting" in the UK. In the recent years, the team has also noted the limitations of geographical expansion as a growth strategy.

While BlaBlaCar remains a market leader at the European level (see Appendix 6), it still needs to iron out some issues. Closer to home in Germany, a country very fond of carpooling, BlaBlaCar is looking for the right monetisation strategy. The Germans who prefer cash payments are reluctant to go through the app to book trips and pay a commission in passing. In the company's home-ground France, the arrival of multiple competitors such as Drivy, iDVroom, and Carpool has reduced the number of active users of BlaBlaCar, although it still retains its leadership position. In Spain, a lawsuit was filed in 2015 by the Spanish Confederation for Bus Transport (Confebus) against the company on the grounds that BlaBlaCar was in effect providing the services of a transport company and that was unfair competition. BlaBlaCar eventually won the case in 2017 based on the argument that it is not a transport company but a broker that brings drivers and passengers together to share the costs of trips and in turn earns money by charging a fee.

Despite its consistent focus on trust, BlaBlaCar is facing certain issues on the customer front. In most of its markets, its existing model is primarily based on the information supplied by the users, which 
has resulted in it being entangled in some legal cases and attracting bad press. A driver in France was arrested in 2014 and later sentenced in 2017, for drugging and sexually assaulting the passengers contacted through the BlaBlaCar platform. In September 2018, an Italian driver was arrested on the French-Italy border because he unknowingly shared the ride with two undocumented immigrants from Paris. The company maintains that the drivers should check their passengers' papers before starting a trip across the border. However, sceptics question the efficacy of this solution as passengers could also be carrying prohibited substances or illegal items in their bags. Even if it is not a direct responsibility of the company, it puts a dent on the BlaBlaCar trusted ecosystem, which it is proud of so far.

\section{The journey continues}

Luckily, on April 24, 2018, Fred is on a domestic trip, and his elderly passengers are gentle and kind. Before dropping them off to their destination, he informs them that they could also use their e-mail to access the services of the platform and delink their Facebook account if they wish so. As he waves goodbye to them and drives towards home, he cannot stop thinking about what lies ahead. The company has existing future plans on new revenue streams. Remaining close to its origin, the company is experimenting in France with a new offering. In April 2017, BlaBlaCar announced its partnership with the car manufacturer Opel and the long-term car rental specialist ALD Automotive that would enable its more than 300,000 French ambassador-level members to rent Opel cars on long-term rentals for a year of more. The move is to encourage its members to shift from the traditional car ownership model to a 'car-as-a-service' model. Within a month, in May 2017, BlaBlaCar also offered its new platform called BlaBlaLines on two short routes in France - Reims to Châlons-en-Champagne $(45 \mathrm{~km})$ and Toulouse to Montauban $(50 \mathrm{~km})$ - to fulfil the daily commuting needs of its members. It remains to be seen how the new services work, but the future looks exciting to Fred, who just reaches his home now.

\section{Questions:}

1. How does BlaBlaCar create value? What is (are) the value proposition(s) of BlaBlaCar? How does it differ from other traditional businesses?

2. Explain the 'chicken and egg' paradox in the context of platform business. How did BlaBlaCar manage to overcome this paradox?

3. Do you think BlaBlaCar is correct in using different pricing models in different markets? Why or why not?

4. Explain the importance of 'trust capital' in the context of C2B2C markets. Suggest ways for maintaining trust in the wake of recent events described in the case. 


\section{Appendix 1: Founders' Profile ${ }^{1}$}

\section{Frédéric Mazzella, Founder and President of BlaBlaCar}

Since pioneering the idea for BlaBlaCar in 2004, Frédéric has led the company to become the world's largest long-distance carpooling community. As a branding and communications enthusiast, Fred has built a global brand whilst relentlessly spreading the word about the virtues of carpooling. Frédéric carries BlaBlaCar's vision of a people-powered travel network enabled by trust and technology, and is passionate about high social impact solutions. Frédéric is a regular speaker at leading international conferences and in the media, where he comments on the fast changing mobility landscape, entrepreneurship, global marketplaces and building trust in online communities. Prior to founding BlaBlaCar, Frédéric held the role of scientific researcher at NASA (USA) and NTT (Japan). He holds an MBA from INSEAD, a Masters in Computer Science from Stanford and a Masters in Physics from Ecole Normale Supérieure (France). Frédéric is also an accomplished classical pianist.

\section{Nicolas Brusson, Co-Founder and CEO of BlaBlaCar}

Prior to becoming Chief Executive Officer in October 2016, Nicolas oversaw BlaBlaCar's global operations and international growth. As Chief Operating Officer, he led the company's corporate development, overseeing eight acquisitions, expansion to twenty markets, and three successive rounds of fundraising. Nicolas is a strong proponent of agile structures that allow quick iterations in fast-growing environments. He is also a supporter of autonomous local teams and acquihires, a strategy he implemented to expand BlaBlaCar's footprint on a global scale. Nicolas is a regular speaker at leading international conferences and in the media, where he comments on the European start-up scene, innovative growth strategies, and mobility. Prior to joining BlaBlaCar in 2011, Nicolas worked for several startups in Silicon Valley during the dotcom boom, before moving on to executive and investor roles, including spending time as a Venture Capitalist at Amadeus Capital Partners in London. He holds an MBA from INSEAD, a Masters in Optics from Ecole Supérieure d'Optique and a Masters in Applied Physics from Paris XI University.

\section{Francis Nappez, Co-Founder and CTO of BlaBlaCar}

Francis leads the technical and product evolution of BlaBlaCar and has been instrumental in building the platform since 2006, allowing it to grow from hosting a few thousand members to millions today. He knows how to turn ambitious ideas into reality, and believes in building robust solutions which can adapt to fast growth and stay relevant for the long-term. Francis cares about building agile crossfunctional teams across locations to deliver efficiently on ambitious objectives. Pragmatic and resultoriented, he is driven by the opportunity to create disruptive solutions which better the user experience. Before joining BlaBlaCar, Francis led major technical developments for big names in European consumer internet which drove impactful disruptions in their respective sectors, including Free and Meetic. Francis holds a degree in Technology and Communications Research from the Joseph Fourier University.

\footnotetext{
${ }^{1}$ Available at: $\underline{\text { https://blog.blablacar.com/about-us/founders }}$
} 


\section{Appendix 2A: Train Strikes in France 2007-2018}

A. October ( 6 days) and November 2007 (10 days): Reform of railway workers 'pension scheme.

B. April 2010 (14 days): Issues of jobs, reorganization by branches and the future of freight.

C. October 2010 (17 days): Pension scheme reform.

D. June 2014 (14 days): Consolidation under the same public holding SNCF and Réseau Ferré de France (RFF, organization that manages the rail network).

E. April to July 2018: 38 days across four months

F. Oct-Dec 2018: Four days

Appendix 2B: Google Trends for the keyword "covoiturage" 2006-2014 w/ strikes

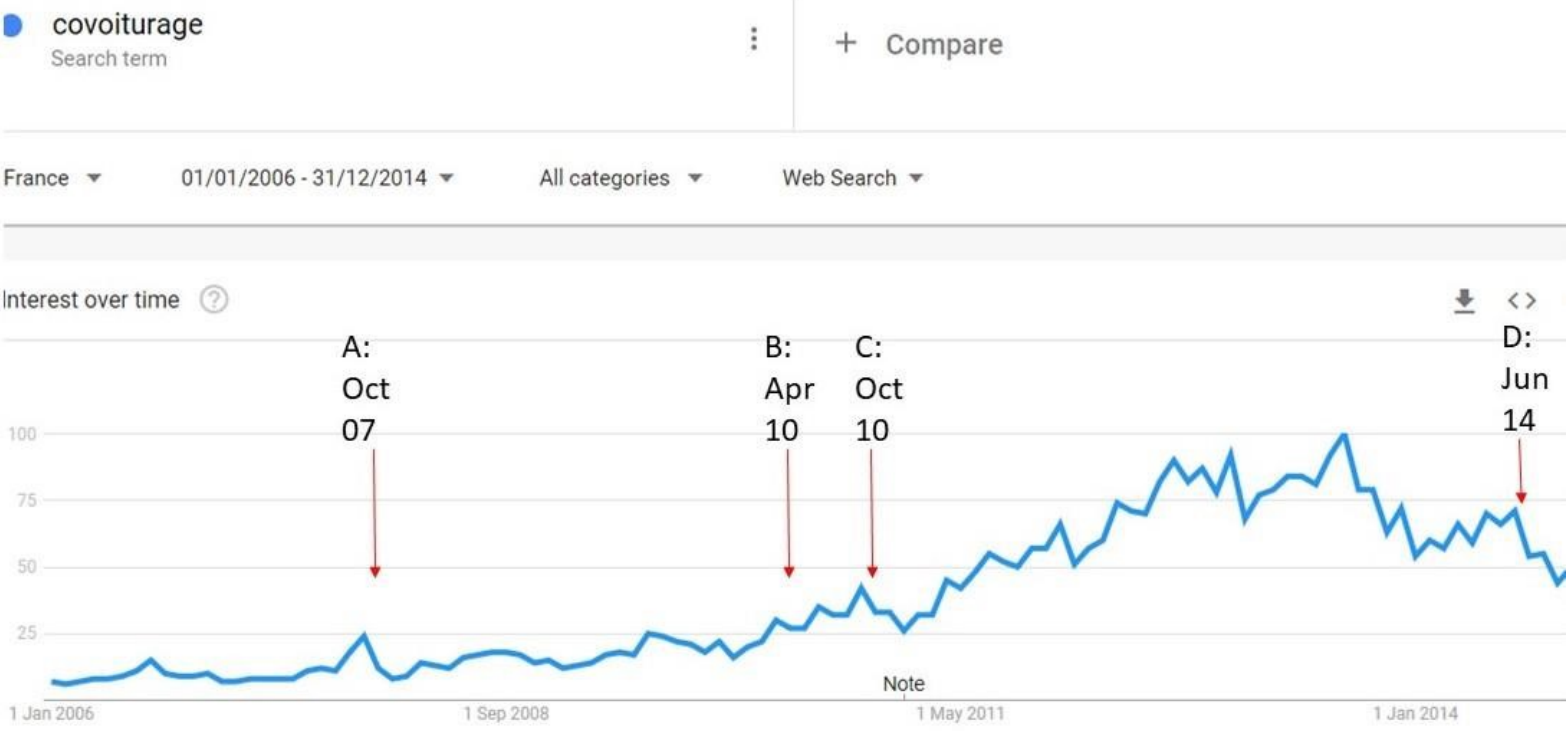

Appendix 2C: Google Trends for the keyword "BlaBlaCar" 2013-2018 w/ strikes

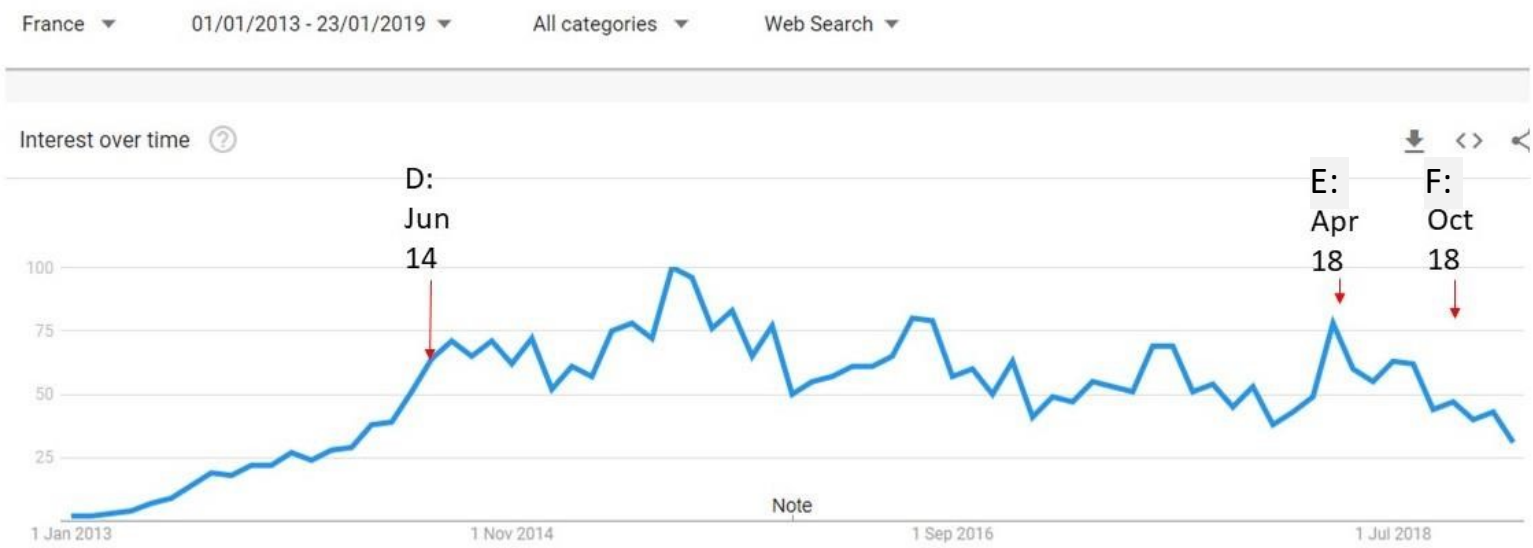


Appendix 3: Summary of BlaBlaCar Venture Capital Funding Rounds ${ }^{1}$

\begin{tabular}{|l|l|l|l|}
\hline Year & Amount & Type & Lead Investor(s) \\
\hline 2009 & $€ 600,000$ & Seed & Founders (including friends and family) \\
\hline 2010 & $€ 1.3 \mathrm{~m}$ & Series A & French VC Jean-David Chamboredon \\
\hline 2012 & $\$ 10 \mathrm{~m}$ & Series B & Accel Partners \\
\hline 2014 & $\$ 100 \mathrm{~m}$ & Series C & $\begin{array}{l}\text { Index Ventures, Accel Partners, ISAI, and Lead Edge } \\
\text { Capital }\end{array}$ \\
\hline 2015 & $\$ 200 \mathrm{~m}$ & Series D & Insight Venture, and Lead Edge Capital \\
\hline 2016 & $€ 21.3 \mathrm{~m}$ & Private Equity & Baring Vostok \\
\hline 2018 & $€ 101 \mathrm{~m}$ & Corporate & SNCF (French National Rail Company) \\
\hline
\end{tabular}

Appendix 4: Year of establishment and revenue model in different markets ${ }^{2}$

\begin{tabular}{|c|c|c|}
\hline Established & Country & Revenue Model \\
\hline 2004 & France & Transaction-fee \\
\hline 2009 & Spain & Transaction-fee \\
\hline 2011 & UK & Transaction-fee \\
\hline \multirow{6}{*}{2012} & Italy & Transaction-fee \\
\hline & Portugal & Transaction-fee \\
\hline & Poland & Transaction-fee \\
\hline & Netherland & Transaction-fee \\
\hline & Luxemburg & Transaction-fee \\
\hline & Belgium & Transaction-fee \\
\hline 2013 & Germany & Transaction-fee \\
\hline \multirow{3}{*}{2014} & Ukraine & Cash for Ride \\
\hline & Russia & Cash for Ride \\
\hline & Turkey & Cash for Ride \\
\hline \multirow{6}{*}{2015} & Hungary & Cash for Ride \\
\hline & Croatia & Cash for Ride \\
\hline & Serbia & Cash for Ride \\
\hline & Romania & Cash for Ride \\
\hline & India & Cash for Ride \\
\hline & Mexico & Cash for Ride \\
\hline \multirow{3}{*}{2016} & Slovakia & Cash for Ride \\
\hline & Czech Republic & Cash for Ride \\
\hline & Brazil & Cash for Ride \\
\hline
\end{tabular}

\footnotetext{
${ }^{1}$ Source: Crunchbase

${ }^{2}$ European Commission (2017). Exploratory study of consumer issues in online peer-to-peer platform markets. Available at: http://ec.europa.eu/newsroom/document.cfm?doc id=46223
} 


\section{Appendix 5a: Dreams Framework ${ }^{1}$}

Declared information forms the bedrock of a trusted online profile. Members declare information such as name, age, a brief description about themselves, among others. This reduces the anonymity of the transaction and introduces an element of familiarity.

Ratings allow for the aggregation of bidirectional feedback from other member where drivers can rate the passengers and vice versa. To ensure fair and honest ratings and to discourage 'revenge ratings', the platform allows members to view their own rating only if they rate their co-travellers within 14 days.

To ascertain that the members are fully engaged and will honour their commitment, the platform allows members to financially commit to the transaction before they start the ride, usually via a prepayment service.

To build the trust, members need to know how much active other members are whether they are drivers or the passengers. More active members on the platform are seen as more trustworthy. Therefore, the app includes the level and frequency of members' activity so that other members could use this information before making a transaction.

User generated information, such as the contact phone number or bank details are moderated by the platform to ensure the authenticity of the users and the transactions. It increases members' trust that the information is authenticated by the platform service provider.

Social network profiles are used to further build the trust by linking members (if they choose to do so) online identity with their profile on the platform. Members can link their Facebook and/or Linkedln profile to their Blablacar account to create trust.

\footnotetext{
${ }^{1}$ Entering the trust age. Available at: https://blog.BlaBlaCar.com/wpcontent/uploads/2016/05/entering-thetrust-age.pdf
} 